\title{
Videocâmeras em biotérios de experimentação: importante ferramenta no controle da contaminação ambiental na microbiota de camundongos
}

\author{
[Interference of environmental contamination in microbiota \\ of mice in experimental facilities] \\ C.A. Muller ${ }^{1}$, S. Ramos $^{2}$, A.O. Saisse ${ }^{2}$, N.R.P. Almosny ${ }^{3}$ \\ ${ }^{1}$ Instituto Oswaldo Cruz - Fiocruz - Rio de Janeiro, RJ \\ ${ }^{2}$ Centro de Criação de Animais de Laboratório - Fiocruz - Rio de Janeiro, RJ \\ ${ }^{3}$ Faculdade de Veterinária - Universidade Federal Fluminense - Niterói, RJ

\section{RESUMO}

O objetivo do presente estudo foi verificar a influência da contaminação ambiental na microbiota dos animais utilizados em experimentação, usando-se videocâmera como ferramenta de controle, a partir da comparação de dois biotérios de experimentação, sendo um protegido com presença de videocâmeras (A) e o outro não (B), quanto ao padrão microbiológico dos camundongos. Para os testes bacteriológicos, foram utilizadas amostras de 222 animais do biotério A e 236 do biotério B; para os testes virológicos, 119 do biotério A e 236 do biotério B; já para os exames parasitológicos, 158 do biotério A e 316 do biotério B. Os dados foram submetidos à análise descritiva e ao teste do Qui-quadrado. Verificou-se uma maior ocorrência de microrganismos e de parasitas no biotério não protegido pelas videocâmeras. Klebsiella pneumoniae, Pasteurella sp. e Pseudomonas $s p$. foram encontradas nos animais de ambos os biotérios, ao passo que vírus e parasitos só foram detectados nos animais no biotério não protegido. Dentre os vírus, nos animais infectados, o de maior ocorrência foi o Vírus da Hepatite de Camundongos (MHV) e, dentre os parasitos, o de maior ocorrência foi Syphacia sp. Concluiu-se que o biotério protegido foi capaz de garantir padrões microbiológicos mais adequados para a experimentação animal, que as videocâmeras são importantes ferramentas de controle e que a prática da biossegurança deve ser constante nas instituições de pesquisa.

Palavras-chave: camundongo, biossegurança, biotério, contaminação, microrganismos

\begin{abstract}
The aim of this study was to investigate the influence of environmental contamination in the microbiota of animals used in experimentation, from the comparison of two experimental animal facilities, one protected with video cameras (A) and one not protected with video cameras (B). Bacteria, viruses and endoparasites have been investigated in both facilities, according to the methodology proposed for each agent. For the bacteriological tests, a sample of 222 animals in facility $A$ and 236 from facility $B$ was used; for the virological tests, 119 from facility $A$ and 236 from facility $B$; and for parasitological examination, 158 from facility $A$ and 316 from facility $B$. The data were submitted to descriptive analysis and to the Chi-square test. The results indicated a higher occurrence of microrganisms and parasites in animals from the unprotected facility. Klebsiella pneumoniae, Pasteurella sp. and Pseudomonas sp. could be detected in the animals from both facilities, whereas viruses and parasites were found only in the unprotected housed mice. Among the viruses in infected animals the most common was the occurrence of Mice Hepatitis Virus (MHV) and among the parasites, the predominant was Syphacia sp. It was concluded that the protected facility was able to ensure microbiological standards more suitable for animal testing, video cameras are important control tools, and the practice of biosecurity must be constant in research institutions.
\end{abstract}

Keywords: mouse, biosafety, facility contamination, microrganism

Recebido em 6 de fevereiro de 2014

Aceito em 27 de fevereiro de 2015

E-mail: camuller@ioc.fiocruz.br 


\section{INTRODUÇÃO}

O conhecimento do padrão microbiológico dos animais de laboratório é de fundamental importância, não só porque pode afetar os animais e as pessoas, mas porque pode também influenciar severamente os resultados dos estudos experimentais. Muitas infecções em roedores são subclínicas, e modificações nos resultados de pesquisas ocorrem por infecções naturais com ausência de manifestações clínicas (Baker, 1998). Considerando que a pesquisa biomédica exige, hoje, o uso somente de animais de alta qualidade, microbiologicamente definidos (NA et al., 2010), cada vez mais têm sido utilizados animais specific pathogen free - SPF, os quais são livres de microrganismos e parasitos específicos, porém não necessariamente livres de outros não específicos. Para se obter esse tipo de status sanitário, é fundamental que os animais sejam criados e mantidos em ambientes protegidos por rigorosas barreiras sanitárias e que ocorra frequente monitoração dos animais, para se ter certeza que contaminantes indesejáveis não se estabeleceram.

Diversos autores (Van Der Logt, 1993; Jacoby e Lindsey, 1997; Shek, 2008; Fontes, 2008) têm enfatizado a importância de ambas as estratégias para prevenção da presença dos agentes biológicos em animais de laboratório: uma rigorosa biossegurança e uma monitorização da saúde dos animais. Os animais devem ser frequentemente monitorados por exames laboratoriais, e o ambiente, controlado por processos de higienização, desinfecção, sanitização e esterilização das áreas. Todo esse processo é denominado de bioproteção. É importante reconhecer que o perfil das infecções em biotérios vem se modificando ao longo dos tempos. Vários agentes infecciosos, os quais eram presentes em biotérios, agora estão ficando mais raros, tais como vírus Sendai, Mycoplasma pulmonis e cestodeos, embora continuem presentes em populações silvestres, assim como possivelmente em amostras armazenadas (Clifford e Watson, 2008). No entanto, vários outros agentes biológicos continuam presentes, assim como o vírus da hepatite do camundongo (MHV) (Clifford e Watson, 2008). Apesar da importância do controle microbiológico, destacado na literatura, observou-se que existem poucos estudos com a finalidade de dar visibilidade aos problemas das infecções nos diversos biotérios em que os animais se encontram, em diferentes países. Destacam-se os estudos de Jacoby e Lindsey (1997), nos EUA, e Seok et al. (2005) e Won et al. (2006), ambos na Coreia, os quais comparam biotérios. O presente estudo foi desenvolvido com a finalidade de identificar se as práticas de biossegurança adotadas são capazes de controlar a microbiota normal, bacteriana, viral e parasitária de camundongos alojados em biotérios de experimentação.

\section{MATERIAL E MÉTODOS}

Foram estudados dois biotérios de experimentação, que foram nomeados de biotério A e biotério B, sendo instalados, no primeiro, videocâmeras. Os procedimentos de rotina nos biotérios de experimentação A e B são: clínica, cirurgia, eutanásia, necropsia, inoculação e coleta de sangue de camundongos, envolvendo diversos tipos de protocolos, cujos projetos foram aprovados pela CEUA da Instituição. Os camundongos são manipulados por pesquisadores, alunos de pós-graduação, técnicos dos laboratórios usuários, por médicos veterinários e técnicos dos biotérios. Cada biotério tem sua equipe exclusiva, constituída por cinco técnicos e um médico veterinário, responsável técnico. Todos os profissionais lotados nos biotérios receberam o mesmo treinamento. $\mathrm{O}$ número de usuários variou entre 15 a 20 pessoas por dia. Foram analisadas microbiologicamente amostras oriundas do ambiente e dos animais de ambos os biotérios. As amostras ambientais de cada biotério foram coletadas antes e depois dos procedimentos de descontaminação, e repetidas a cada 90 dias. Já as amostras dos animais foram coletadas no momento de sua introdução nos biotérios e repetidas a cada 90 dias, durante 18 meses. O protocolo experimental $n^{\circ}$ L-008/09 foi aprovado pela Comissão de Ética no Uso de Animais (CEUA) da Instituição.

O biotério A apresentava um rigoroso controle de acesso de pessoal, possuindo videocâmeras que faziam a filmagem da entrada e seu corredor. Já o biotério $\mathrm{B}$ não possuía tais câmeras. Em ambos os biotérios foram realizados os mesmos procedimentos de higienização e descontaminação e foram sempre preconizados equipamentos de proteção individual. Dessa forma, a grande diferença entre os biotérios 
refere-se à obediência rigorosa às boas práticas nas dependências dos biotérios, o que foi ocasionado pela presença de videocâmeras.

Ambos os biotérios, sem a presença de animais, foram submetidos à descontaminação por solução de formol a 37\% (dia 0). Após 10 dias, sem a ocorrência de entrada de pessoal e animais, foi realizada a coleta de material do ambiente em cada um dos biotérios para fins de investigação de presença de bactérias.

Após a descontaminação, iniciou-se com a higienização para o procedimento básico de proteção em um ambiente e, após sua conclusão, prosseguiu-se com a etapa de desinfecção (Cloreto de Benzalcônio a 50\%) e sanitização ambiental (monoperssulfato de potássio em solução de $1 \%$ ). A higienização e a desinfecção foram realizadas na sequência teto, parede e piso, respectivamente (Ingraham e Fleischer, 2003).

Durante a realização da atividade, atentou-se para os sistemas de vedação de portas, visores e pias. Os materiais de desinfecção foram lavados com água e desinfetados com álcool $70 \%$, para então serem transportados para a área protegida. Os materiais foram transportados através de autoclave de barreira ou porto de passagem, dependendo de suas características físicoquímicas, como tamanho, resistência a ácido peracético e possibilidade de autoclavação (Rutala e Werber, 2004).

A avaliação da qualidade do status sanitário de cada ambiente foi obtida através de exame laboratorial realizado com auxílio de swabs, passados em pontos pré-determinados após os procedimentos de desinfecção, semeados em placas contendo Ágar sangue e processadas de acordo com as técnicas bacteriológicas correntes.

Após a obtenção das amostras ambientais de cada um dos dois biotérios, as quais foram coletadas com auxílio de swabs estéreis, amostras das portas, teto, saídas de ar condicionado, chão, paredes, racks e estantes ventiladas para fins de investigação bacteriológica, segundo as recomendações da FELASA (Nicklas et al., 2002) e verificação de resultados negativos para os microrganismos investigados, realizou-se nova higienização do ambiente e então foi liberada a entrada de animais.
A partir de então, a cada 90 dias, animais foram enviados para o Laboratório de Controle de Qualidade Animal do Centro de Criação de Animais de Laboratório - Cecal/Fiocruz, para o monitoramento sanitário, onde foram coletadas as amostras para investigação microbiológica e parasitária durante um período de 18 meses, em ambos os biotérios. De cada um dos animais selecionados para cada bateria de testes, coletaram-se amostras de fezes para o exame parasitológico, de sangue para sorologia viral, e fragmentos de traqueia e intestino durante a necropsia para realização de cultura.

Cada um dos biotérios estudados tem uma população de cerca de 3.000 camundongos, machos e fêmeas, de diferentes linhagens e idades. Dessa forma, 222 animais $(7,44 \%)$ do biotério A e $316(10,54 \%)$ do biotério B foram randomicamente selecionados para o estudo, totalizando 538 animais. Tomou-se o cuidado de incluir animais de todos os racks e estantes ventiladas de cada biotério.

Para os testes bacteriológicos, foram utilizadas amostras de 222 animais do biotério A e 236 do biotério $\mathrm{B}$; para os testes virológicos, 119 do biotério A e 236 do biotério B; já para os exames parasitológicos, utilizaram-se 158 do biotério A e 316 do biotério $\mathrm{B}$.

O isolamento bacteriano foi realizado por cultura em placas com meios específicos para o crescimento de bactérias patogênicas específicas, e a identificação, realizada no equipamento VITEK - Biomeriux. O sistema automatizado permite a agilidade no processo de identificação e na validação dos resultados, minimizando possíveis erros operacionais.

O diagnóstico das viroses foi realizado pela técnica de ELISA, com kits comerciais produzidos para cada enfermidade, de acordo com as recomendações dos fabricantes. Amostras positivas e próximas ao ponto de corte foram obrigatoriamente repetidas para confirmação.

Os exames parasitológicos foram divididos em duas etapas: $\mathrm{O}$ ectoparasitológico, que consistiu na inspeção do pelo do animal à microscopia estereoscópica, quando foram pesquisados ácaros e piolhos. Já o endoparasitológico foi feito pela técnica da fita adesiva de celofane e técnicas coproparasitológicas. Os testes qualitativos são 
complementados com análises quantitativas, em que a carga parasitária encontrada foi simbolizada com a referência cruzes $(+\mathrm{a}++++)$.

As amostras foram submetidas às análises para investigação de bactérias, vírus e parasitos, de acordo com as recomendações da Federation for Laboratory Animal Science Associations FELASA (Nicklas at al., 2002). Para a investigação de agentes bacterianos, procedeu-se à cultura bacteriológica específica para Bordetella bronchiseptica, Citrobacter rodentium, Klebsiella pneumoniae, Pasteurella sp., Pseudomonas sp., Salmonella sp., Staphylococcus haemolyticus, Staphylococcus aureus, Streptococcus pneumoniae e Streptococcus $\beta$-hemolítico. A presença de anticorpos anti-Cillia-associated respiratory Bacillus e anti-Mycoplasma pulmonis foi avaliada por ELISA.

Para a investigação de anticorpos direcionados aos principais vírus dos camundongos, testou-se por ELISA anticorpos anti: Vírus Diminuto do Camundongo (MVM), Vírus Hepatite de Camundongos (MHV), Pneumovírus (PVM), Reovírus tipo 3, Sendai Vírus, Vírus Coriomeningite Linfocítica (LCMV), Poliomavírus, Ectromelia vírus e Vírus Encefalomielite Murina (TMEV). Já para as investigações parasitológicas, investigou-se a presença de pulgas, ácaros e piolhos por microscopia direta, e de Syphacia sp., Aspiculuris tetraptera, Rodentolepis nana, Tricomonídeos, Spironucleus muris, Giardia muris e Entamoeba sp. por exame direto da mucosa intestinal (EDMI).

Os dados foram submetidos à análise descritiva $\mathrm{e}$ teste não paramétrico do Qui-quadrado $\left(X^{2}\right)$. Consideraram-se estatisticamente significativas associações com valor de $\mathrm{P}<0,05$.

\section{RESULTADOS}

As bactérias foram os únicos patógenos cuja presença foi observada nas amostras dos animais do biotério A, sendo elas $K$. pneumoniae, Pseudomonas sp. e Pasteurella sp.. De todos os patógenos bacterianos observados, verificou-se que no biotério B foi detectada a presença de $C$. rodentium, $K$. pneumoniae, Pasteurella sp.,
Pseudomonas sp., além de anticorpos antiMycoplasma, conforme Tab. 1.

No que se refere aos anticorpos específicos para as principais viroses de camundongos, no biotério A nenhum foi evidenciado, enquanto no biotério B verificou-se a presença de anticorpos anti-MVM, MHV, PVM, Reovírus tipo 3, LCM e TMEV. (Tab. 1).

Quanto à presença de parasitos, no biotério $\mathrm{A}$ nenhum dos parasitos pesquisados foi evidenciado e verificou-se, no biotério $\mathrm{B}$, a ocorrência de Syphacia sp., Aspiculuris tetraptera, Tricomonídeos, Spironucleus muris e Giardia muris (Tab. 1).

No que se refere ao número de amostras positivas, verifica-se, no caso das bacterioses, que Pasteurella $s p$. foi o agente mais frequentemente encontrado no biotério $\mathrm{A}$, verificado em oito das 222 amostras testadas, seguido de Klebsiella pneumoniae (5/222) e Pseudomonas sp. (2/222). No biotério B, Pasteurella sp. foi também o agente mais frequentemente encontrado (8/296), seguido de Klebsiella pneumoniae (7/296), Pseudomonas sp. e Mycoplasma pulmonis (3/296 cada), Staphylococcus haemolyticus (2/296) e Citrobacter rodentium (1/296). A comparação do número de amostras positivas dos dois biotérios, em função de sua baixa frequência, não se mostrou estatisticamente significativa (Tab. 2).

No que se refere ao número de amostras positivas, no caso das viroses, verificou-se que nenhum dos agentes pesquisados foi evidenciado no biotério A. No biotério B, o vírus da Hepatite de Camundongos (MHV) foi significativamente o agente mais encontrado (146/236), seguido do Vírus da Encefalomielite Murina - TMEV (85/236), Vírus Diminuto do Camundongo MVM (65/236) e, em menores proporções, o Vírus da Coriomeningite Linfocítica - LCMV (15/236), Pneumovírus (7/236) e Reovírus tipo 3 (5/236). Os demais vírus não foram evidenciados. A comparação estatística do número de amostras positivas dos dois biotérios mostrou-se estatisticamente significativa no caso do MHV, TMEV e MVM (Tab. 3). 
Videocâmeras em biotérios...

Tabela 1. Presença de bactérias, vírus e parasitos nos biotérios A e B de camundongos

\begin{tabular}{|c|c|c|c|}
\hline \multirow{2}{*}{ Patógeno } & & \multicolumn{2}{|c|}{ Camundongos } \\
\hline & & Biotério A & Biotério B \\
\hline \multirow{12}{*}{ Bactérias } & Bordetella bronchiseptica & - & - \\
\hline & Cillia-assoc resp. Bacillus & - & - \\
\hline & Citrobacter rodentium & - & $\mathbf{X}$ \\
\hline & Klebsiella pneumoniae & $\mathbf{X}$ & $\mathbf{X}$ \\
\hline & Mycoplasma pulmonis & - & $\mathbf{X}$ \\
\hline & Pasteurella spp & $\mathbf{X}$ & $\mathbf{X}$ \\
\hline & Pseudomonas spp & $\mathbf{X}$ & $\mathbf{X}$ \\
\hline & Salmonella spp & - & - \\
\hline & Staphylococcus haemolyticus & - & - \\
\hline & Staphylococcus aureus & - & - \\
\hline & Streptococcus pneumoniae & - & - \\
\hline & Streptococcus $\beta$-hemolítico (grupo D) & - & - \\
\hline \multirow{9}{*}{ Vírus } & Vírus Diminuto do Camundongo (MVM) & - & $\mathbf{X}$ \\
\hline & Vírus Hepatite de Camundongos (MHV) & - & $\mathbf{X}$ \\
\hline & Pneumovírus (PVM) & - & $\mathbf{X}$ \\
\hline & Reovírus tipo 3 & - & $\mathbf{X}$ \\
\hline & Sendai Vírus & - & - \\
\hline & Vírus da Coriomeningite Linfocítica (LCM) & - & $\mathbf{X}$ \\
\hline & Poliomavírus & - & - \\
\hline & Ectromelia vírus & - & - \\
\hline & Vírus da Encefalomielite Murina (TMEV) & - & $\mathbf{X}$ \\
\hline \multirow{8}{*}{ Parasitos } & Pulgas, ácaros e piolhos & - & - \\
\hline & Syphacia spp. & - & $\mathbf{X}$ \\
\hline & Aspiculuris tetráptera & - & $\mathbf{X}$ \\
\hline & Rodentolepis nana & - & - \\
\hline & Tricomonídeos & - & $\mathbf{X}$ \\
\hline & Spironucleus muris & - & $\mathbf{X}$ \\
\hline & Giardia muris & - & $\mathbf{X}$ \\
\hline & Entamoeba sp. & - & - \\
\hline
\end{tabular}

Tabela 2. Número de amostras positivas para a pesquisa de bactérias nos biotérios A e B de camundongos

\begin{tabular}{lccc}
\hline Bactérias & Biotério A & Biotério B & p-valor $\chi^{2}$ \\
\hline Bordetella bronchiseptica & $0 / 222$ & $0 / 296$ & - \\
Cillia-assoc resp. Bacillus & $0 / 222$ & $0 / 296$ & - \\
Citrobacter rodentium & $0 / 222$ & $1 / 296$ & 0,386 \\
Klebsiella pneumoniae & $5 / 222$ & $7 / 296$ & 0,933 \\
Mycoplasma pulmonis & $0 / 222$ & $3 / 296$ & 0,132 \\
Pasteurella sp. & $8 / 222$ & $8 / 296$ & 0,552 \\
Pseudomonas sp. & $2 / 222$ & $3 / 296$ & 0,897 \\
Salmonella sp. & $0 / 222$ & $0 / 296$ & - \\
Staphylococcus haemolyticus & $0 / 222$ & $2 / 296$ & 0,259 \\
Staphylococcus aureus & $0 / 222$ & $0 / 296$ & - \\
Streptococcus pneumoniae & $0 / 222$ & $0 / 296$ & - \\
Streptococcus $\beta$-hemolítico (grupo D) & $0 / 222$ & $0 / 296$ & - \\
\hline
\end{tabular}


Tabela 3. Número de amostras positivas para a pesquisa de anticorpos antivirais nos biotérios A e B de camundongos

\begin{tabular}{lccc}
\hline Vírus & Biotério A & Biotério B & p-valor $\chi^{2}$ \\
\hline Vírus Diminuto do Camundongo (MVM) & $0 / 119$ & $65 / 236$ & $<0,0005$ \\
Vírus Hepatite de Camundongos (MHV) & $0 / 119$ & $146 / 236$ & $<0,005$ \\
Pneumovírus (PVM) & $0 / 119$ & $7 / 236$ & 0,058 \\
Reovírus tipo 3 & $0 / 119$ & $5 / 236$ & 0,110 \\
Sendai Vírus & $0 / 119$ & $0 / 236$ & - \\
Vírus Coriomeningite Linfocítica (LCM) & $0 / 119$ & $15 / 236$ & 0,005 \\
Poliomavírus & $0 / 119$ & $0 / 236$ & - \\
Ectromelia vírus & $0 / 119$ & $0 / 236$ & - \\
Vírus Encefalomielite Murina (TMEV) & $0 / 119$ & $85 / 236$ & $<0,0005$ \\
\hline
\end{tabular}

Quanto à presença de parasitos, nenhum dos parasitos estudados foi evidenciado no biotério A. No biotério B, Syphacia sp. foi significativamente o agente mais encontrado (161/316), seguido em menores proporções por Spironucleus muris (13/316), Tricomonídeos
(7/316) e Giardia muris (1/316). A comparação estatística do número de amostras positivas dos dois biotérios mostrou-se estatisticamente significativa somente no caso de Syphacia sp. (Tab. 4). Não foram evidenciados ectoparasitos em nenhum dos animais testados.

Tabela 4. Número de amostras positivas para a pesquisa de parasitos nos biotérios A e B de camundongos

\begin{tabular}{lccc}
\hline Parasitos & Biotério A & Biotério B & p-valor $\chi^{2}$ \\
\hline Pulgas, ácaros e piolhos & $0 / 158$ & $0 / 316$ & - \\
Syphacia spp. & $0 / 158$ & $\mathbf{1 6 1 / 3 1 6}$ & $<0,0005$ \\
Aspiculuris tetráptera & $0 / 158$ & $\mathbf{2 / 3 1 6}$ & 0,316 \\
Rodentolepis nana & $0 / 158$ & $0 / 316$ & - \\
Tricomonídeos & $0 / 158$ & $\mathbf{7 / 3 1 6}$ & 0,059 \\
Spironucleus muris & $0 / 158$ & $\mathbf{1 3 / 3 1 6}$ & 0,010 \\
Giardia muris & $0 / 158$ & $\mathbf{1 / 3 1 6}$ & 0,475 \\
Entamoeba spp. & $0 / 158$ & $0 / 316$ & - \\
\hline
\end{tabular}

\section{DISCUSSÃO}

Os resultados indicaram que a maior contaminação e concentração de agentes ocorreu no biotério $\mathrm{B}$, isto é, no biotério em que não havia as videocâmeras, o que já era esperado neste estudo. Nos poucos estudos encontrados na literatura científica que compararam animais oriundos de biotérios com barreiras com animais oriundos de biotérios convencionais (Seok et al., 2005; Won et al., 2006), os resultados também indicaram maior contaminação dos animais nos ambientes convencionais, o que equivale a dizer não protegido neste estudo.

O tipo de estratégia adotada neste estudo, visando diminuir a contaminação ambiental do biotério A, acabou por realçar a importância da conscientização e treinamento do pessoal que manipula os animais, sejam eles os técnicos que cuidam dos animais e/ou pesquisadores. O fato de o biotério A ter uma câmera filmando as atividades diárias funcionou como uma permanente vigilância para que todos os procedimentos ocorridos em seu interior estivessem de acordo com as regulamentações e recomendações. Tal fato reforça a abordagem de Pritt et al. (2007), que destacaram a importância do treinamento do pessoal quando se objetiva trabalhar com biossegurança. Os autores citados destacaram a "cultura de biossegurança" como um componente crítico para que qualquer instituição seja bem-sucedida, sendo que tal cultura depende basicamente de um efetivo programa de treinamento de pessoal em todos os níveis. Embora no presente estudo não tenha sido 
realizado um treinamento específico e diferenciado do pessoal que frequentava o biotério A, acredita-se que a constante filmagem das áreas de manipulação dos animais assegurou a perfeita implementação do que Pritt et al. (2007) chamaram de "cultura da biossegurança".

As bactérias encontradas no presente estudo, em ambos os biotérios, Klebsiella pneumoniae, Pasteurella sp. e Pseudomonas sp., não representam achados incomuns. Na investigação de Won et al. (2006), Pasteurella pneumotropica e Pseudomonas aeruginosa também estavam presentes nos biotérios com barreiras e nos convencionais, o que coincide com os achados do presente estudo, sendo que Klebsiella pneumoniae não foi investigada por eles, o que não permite a comparação com nosso estudo. Pasteurella pneumotropica foi relatada em 50\% dos biotérios com barreiras e em $54 \%$ dos convencionais no estudo de Won et al. (2006), o que revela ser um achado frequente em biotérios na Coreia. Pseudomonas aeruginosa, embora em menor percentual, também apareceu em 5\% dos biotérios com barreiras e em 15\% dos biotérios convencionais. Tais resultados, assim como a literatura pertinente, sugerem a dificuldade de se controlar a presença dessas bactérias, mesmo em biotérios com maior controle que os convencionais. Com isso, pode-se dizer que esse resultado era esperado também em nossos biotérios. Segundo Barthold (2008), Pasteurella pneumotropica é um patógeno oportunista que pode ser considerado normal na microflora intestinal de camundongos silvestres e também de muitos animais convencionais; porém, quando ela é eliminada, o seu nicho entérico é ocupado por Klebsiella, Proteus ou outras enterobactérias. Nesse sentido, o que Barthold (2008) questiona é o significado desses achados frequentes dessa bactéria, isto é, até que ponto se deve pensar em eliminá-las. Esse questionamento também permite ver a importância desse tipo de monitoramento dos animais, até mesmo para se rediscutir a busca por certos microrganismos.

Já Mycoplasma pulmonis, que foi detectado somente no biotério não protegido neste estudo, pode ser identificado como a bactéria responsável pela maioria das infecções pulmonares em camundongos (Sirois, 2007), sendo reconhecido como associado a enfermidades em camundongos desde 1937 (Barthold, 2008). Na Coreia, Mycoplasma pulmonis apareceu em 2,6\% (1 em 38) dos biotérios de camundongos com barreiras e em $69 \%$ dos biotérios convencionais (Won et al., 2006). Já no estudo de Seok et al. (2005), Mycoplasma foi detectado apenas em amostras de camundongos de um biotério convencional dentre dois e em nenhum dos três biotérios com barreiras investigados. Em inquérito realizado nos EUA, em 1996, a ocorrência de Mycoplasma ficou abaixo de 5\% nas amostras oriundas de animais de biotérios com barreiras e cerca de $15 \%$ em biotérios convencionais (Jacoby e Lindsey, 1997). Tais achados, assim como o nosso, demonstram que o esforço das barreiras ou bioproteção é capaz de evitar enfermidades nos animais por Mycoplasma pulmonis.

De fato, a fim de erradicar esse agente, foram sugeridos dois métodos, a rederivação por cesareana e o uso e cuidados com os animais em ambientes especificamente designados (Seok et al., 2005). Em revisão recente sobre o tema de enfermidades persistentes, Clifford e Watson (2008) afirmaram que Mycoplasma pulmonis, que era bastante prevalente na América do Norte há cerca de vinte anos, havia praticamente desaparecido em 2007. Os autores atribuem tal fato a razões institucionais e a razões intrínsecas ao agente biológico. Destacamos aqui que essas chamadas razões institucionais estão diretamente ligadas ao esforço de se garantir barreiras adequadas (Jacoby e Lindsey, 1997; Seok et al., 2005; Won et al., 2006).

Dentre todos os microrganismos encontrados, o de maior ocorrência foi o Vírus da Hepatite de Camundongos (MHV). Tal achado coincide com dados da literatura, já que Won et al. (2006), em seu estudo na Coreia, encontraram esse vírus em mais de $40 \%$ dos biotérios convencionais investigados. Em 1996, nos EUA, uma pesquisa nacional indicou que mais de $72 \%$ das instituições com biotérios convencionais apresentavam o MHV, que também foi encontrado em $12 \%$ das instituições que possuíam biotérios com barreiras (Jacoby e Lindsey, 1997). Outros autores (Clifford e Watson, 2008) também relataram a persistência do MHV nas colônias de camundongos. Clifford e Watson (2008) destacaram que, embora o MHV apresente uma relativa fragilidade ambiental quando comparado a outros agentes, sua alta capacidade de persistir em biotérios se deve à sua capacidade de infectar rapidamente 
vários animais, visto que é altamente contagioso e disseminável. No entanto, os mesmos autores (Clifford e Watson, 2008) destacam que a eliminação do MHV é mais fácil do que de outros agentes, já que não persistem no ambiente. Como a transmissão se dá por via oronasal, contato direto, fômites e através da placenta, é necessário um controle dos fômites e testagem de animais que chegam a fim de se fazer a eliminação do vírus. De fato, em nosso biotério A, o MHV não foi encontrado, embora no biotério $\mathrm{B}$ tenha sido o mais importante agente biológico encontrado, o que demonstra a possibilidade de seu controle pelas boas práticas de biossegurança em biotérios.

O vírus da Coriomeningite Linfocítica (LCMV), detectado no biotério $\mathrm{B}$, também foi detectado em $15 \%$ dos biotérios convencionais na Coreia (Won et al., 2006). Devido ao potencial zoonótico desse vírus, que em humanos pode causar sintomas similares aos da gripe, os animais infectados devem ser eliminados da colônia. Esse vírus é pouco investigado em diversos biotérios e, nos EUA, Jacoby e Lindsey (1997) revelaram que $20 \%$ dos biotérios investigados não faziam testes para monitorização do LCMV.

O vírus diminuto do Camundongo (MVM), detectado somente no biotério $\mathrm{B}$ no presente estudo, também apareceu em $8 \%$ dos biotérios convencionais no estudo de Won et al. (2006) e em nenhum dos com barreiras na Coreia. O MVM era o único parvovírus de camundongo conhecido nos anos 80 e permanece prevalente nos dias atuais (Clifford e Watson, 2008). As razões pelas quais a infecção por parvovírus continua aparecendo nos biotérios provavelmente se relaciona mais com a dificuldade de erradicação do que com uma possível reintrodução. Isso ocorre porque eles permanecem infectantes por longos períodos no ambiente (Yang et al., 1995) e são difíceis de serem inativados, permanecendo por longos períodos também nos animais infectados (Smith et al., 1993). São mais difíceis de serem detectados do que muitos outros agentes (Besselsen et al., 2000). Nesses casos, com vistas a uma erradicação do vírus, as recentes propostas de desenvolvimento de uma melhor tecnologia é a implantação de racks e gaiolas microisoladoras (Smith et al., 2007).

O vírus Sendai, que é o principal agente causador de doenças respiratórias em camundongos, foi detectado em $46 \%$ dos biotérios convencionais no estudo de Won et al. (2006). Também apareceu em camundongos convencionais no estudo de Seok et al. (2005) e em mais de $20 \%$ das instituições convencionais (e menos de 5\% nas SPF) em um estudo americano de 1996 (Jacoby e Lindsey, 1997). No presente estudo, tal vírus não foi evidenciado em nenhum dos biotérios. De fato, em 2007, de acordo com relato de Clifford e Watson (2008), o vírus Sendai, juntamente com o Mycoplasma pulmonis, praticamente desapareceram nos EUA.

O vírus da Encefalomielite Murina Theiler's (TMEV) também só foi evidenciado no presente estudo no biotério B (não bioprotegido). Em estudo realizado nos EUA, em 1996, o TMEV foi detectado em mais de $30 \%$ dos camundongos de biotérios convencionais e em quase $5 \%$ dos biotérios com barreiras (Jacoby e Lindsey, 1997). O TMEV permanece moderadamente prevalente em biotérios de camundongos, outrossim, as razões dessa continuação não têm sido facilmente detectadas (Clifford e Watson, 2008).

O fato de não terem sido encontrados pulgas, ácaros e piolhos em nenhum dos biotérios, especialmente considerando o tempo de duração da pesquisa (colheitas de amostras por mais de um ano), revela que não há persistência ambiental dos ovos desses parasitos nesses ambientes. Tal fato evidencia que os processos de descontaminação dependentes do uso de biocidas no ambiente, tanto no que se refere à qualidade dos produtos usados quanto à ação mecânica na sua distribuição, foram eficientes.

Os protozoários investigados, Giardia muris $e$ Spironucleus muris foram encontrados no biotério $\mathrm{B}$, devido à resistência dos cistos e o tempo de infectividade, o que coincide com dados da literatura, já que Won et al. (2006) relataram a presença de protozoários em $85 \%$ dos biotérios convencionais e mesmo nos biotérios com barreiras (42\%). 


\section{CONCLUSÕES}

Os resultados indicam que a constante filmagem das áreas de manipulação dos animais, mesmo sem a realização de um treinamento específico e diferenciado do pessoal que frequentava o biotério $\mathrm{A}$, assegurou obediência rigorosa às boas práticas de biossegurança em todos os níveis nas dependências dos biotérios, e que isso gerou diferença quanto à qualidade microbiológica dos animais, sendo o biotério A capaz de assegurar um melhor padrão microbiológico dos animais. As práticas de biossegurança adotadas foram capazes de controlar a microbiota normal, bacteriana, viral e parasitária de camundongos alojados em biotérios de experimentação protegidos por videofilmagem.

\section{REFERÊNCIAS}

BAKER D.G. Natural pathogens of laboratory mice, rats, and rabbits and their effects on research. Clin. Microbiol. Rev., v.11, p.231-266, 1998.

BARTHOLD, S. Microbes and the evolution of scientific fancy mice. ILAR J., v.49, p.265-271, 2008.

BESSELSEN, D.G.; WAGNER, A.M.; LOGANBILL, J.K. Effect of mouse strain and age on detection of mouse parvovirus 1 by use of serologic testing and polymerase chain reaction analysis. Comp. Med., v.50, p. 498-502, 2000.

CLIFFORD, C. B.; WATSON, J. Old enemies, still with us after all these years. ILAR J., v.49, p.291-302, 2008.

FONTES, B. Institutional responsibilities in contamination control in research animals and occupational health and safety for animal handlers. ILAR J., v.49, p.326-337, 2008.

INGRAHAM, A.; FLEISCHER, T. M. Desinfectants in laboratory animal science: what are they and who says they work? Lab. Anim., v.32, p.36-40, 2003.

JACOBY, R. O.; LINDSEY, J.R. Health care for research animals is essential and affordable. FASEB J., v.11, p.606-609, 1997.
NA, Y.R.; SEOK, S.H.; LEE, H.Y. et al. Microbiological quality assessment of laboratory mice in Korea and recommendations for quality improvement. Exp. Anim., v.59, p.25-33, 2010.

NICKLAS W.; BANEUX P.; BOOT R. et al. Recommendations for the health monitoring of rodent and rabbit colonies in breeding and experimental units. Lab. Anim., v.36, p.20-42, 2002.

PRITT, S.; HANKENSON, F.C.; WAGNER, T.; TATE, M. The basics of animal biosafety and biocontainment training. Lab. Anim., v.36, p.31$38,2007$.

RUTALA, W.A.; WERBER, D.J. The benefits of surface desinfection. Am. J. Infect. Control, v.32, p.226-231, 2004.

SEOK, S.; PARK, J.; CHO, S. et al. Health surveillance of specific pathogen-free and conventionally- Housed Mice and rats in Korea. Exp. Anim., v.54, p.85-92, 2005.

SHEK, W. R. Role of housing modalities on management and surveillance strategies for adventitious agents of rodents. ILAR J., v.49, p.316-325, 2008.

SIROIS, M. Medicina de animais de laboratório: princípios e procedimentos. São Paulo: Rocca, 2007. 344p.

SMITH, A.L.; JACOBY, R.O; JOHNSON E.A. et al. In vivo studies with an "orphan" parvovirus of mice. Lab. Anim., v.43, p.175-182, 1993.

SMITH, P.C.; NUCIFORA, M.; REUTER, J.D.; COMPTON, S.R. Reliability of soiled bedding transfer for detection of mouse parvovirus and mouse hepatite virus. Comp. Med., v.57, p.90-96, 2007.

VAN DER LOGT, J.T. Microbiological effects and quality control in laboratory rodents. FRAR course on laboratory approaches to aging. Aging, v.5, p.317-327, 1993

WON, Y.; JEONG, E.; PARK, H. et al. Microbiological contamination of laboratory mice and rats in Korea from 1999 to 2003. Exp. Anim., v.55, p.11-16, 2006.

YANG, F.C.; PATURZO, F.X.; JACOBY, R.O. Environmental stability and transmission of rat virus. Lab. Anim., v.45, p.140-144, 1995. 